\title{
Determination of Phthalate Esters in Beverages and Water Samples by Solid Phase Extraction with Resin Based COFs as Filler
}

\author{
Yunjie Ma ${ }^{(}$, Xin Gao, Yang Ruan, Hang Cui, Li Zhang, Wei Zhang *(i) and Shaoyan Wang*
}

Citation: Ma, Y.; Gao, X.; Ruan, Y.; Cui, H.; Zhang, L.; Zhang, W.; Wang, S. Determination of Phthalate Esters in Beverages and Water Samples by Solid Phase Extraction with Resin Based COFs as Filler. Water 2021, 13, 3338. https://doi.org/10.3390/ w13233338

Academic Editor: Laura Bulgariu

Received: 25 October 2021

Accepted: 21 November 2021

Published: 24 November 2021

Publisher's Note: MDPI stays neutral with regard to jurisdictional claims in published maps and institutional affiliations.

Copyright: (c) 2021 by the authors. Licensee MDPI, Basel, Switzerland. This article is an open access article distributed under the terms and conditions of the Creative Commons Attribution (CC BY) license (https:// creativecommons.org/licenses/by/ $4.0 /)$.
School of Chemical Engineering, Liaoning Provincial Key Laboratory of Fine Separation Technique, University of Science and Technology, Liaoning, Anshan 114051, China; cda0429@163.com (Y.M.); askdgx@163.com (X.G.); realruanyang@163.com (Y.R.); cuihang703@163.com (H.C.); zl20040306113@163.com (L.Z.)

* Correspondence: askdzw@163.com or askdzw@ustl.edu.cn (W.Z.); wangshaoyan@ustl.edu.cn (S.W.)

\begin{abstract}
Resin based covalent organic framework material was used as filler for solid phase extraction (SPE), and the solid phase extraction effect was compared with that of traditional COF material (TpBD COFs). The enrichment capacity of four phthalate esters (dimethyl phthalate, diethyl phthalate, dibutyl phthalate, dioctyl phthalate) in beverage samples was investigated by SPE. Adsorption experiments showed that the kinetic adsorption behavior of COF materials for phthalate esters (PAEs) was more consistent with the quasi-second-order kinetic adsorption model, and the static adsorption behavior is more in line with the Freundlich isothermal adsorption model. Solid phase extraction experiments proved that the SPE column prepared with two COF materials as adsorbents had good adsorption effects, high recovery (water: $97.99-100.56 \%$ and beverage: $97.93-100.23 \%$ ) and were reusable (50 cycles), which could meet the requirements for trace detection of phthalate ester. It was found that the solid phase extraction effect was better than the four types of commercial SPE columns. The new COF material reduced the cost of monomer use and provided the possibility for its industrial production. Meanwhile, it also provided a new feasible scheme for enriching trace phthalate esters in practical samples.
\end{abstract}

Keywords: resin-based COFs; phthalate esters; solid phase extraction; trace analysis

\section{Introduction}

As an environmental hormone, phthalate esters (PAEs) have been widely used as plasticizers of polymer materials and as solvents or emulsifiers, which have caused serious threats to human health (including organs, blood system, reproductive system, and certain carcinogenicity [1,2]). Among them, dimethyl phthalate (DMP) and diethyl phthalate (DEP) are often used as stationary liquid and lubricant for gas chromatography and deodorant, respectively [3-5], while dibutyl phthalate (DBP) and dioctyl phthalate (DOP) have been used as plasticizers of nitrocellulose and polyvinyl chloride, respectively [6-9]. These phthalate esters are widely found in the environment, causing potential harm to human health $[10,11]$, and the existence of these interferences in environmental samples is very small. In most cases, solid phase extraction (SPE) is used to analyze and enrich these substances in environmental systems. This technology has the characteristics of less solvent consumption, good reproducibility, and high selectivity [12], and is widely used in trace and poison analysis [13,14] and environmental detection [15]. The key of this technology lies in the selection of adsorbents. Generally, porous materials with large specific surface area and stable properties are selected. However, traditional adsorption materials, such as resin, graphene, and carbon nanotubes, are not suitable for the detection of trace PAEs as SPE fillers due to their low adsorption efficiency and low reusability. Novel adsorbents such as metal organic framework materials, magnetic adsorbents, and molecularly imprinted adsorbents have good adsorption capacities, which are suitable for 
the study of PAEs as solid phase extraction fillers [16-20]. As a new adsorption material, covalent organic framework materials (COFs) are considered as high efficiency adsorbents with characteristics such as a large specific surface area, porous structure and good thermal stability, which is suitable for the enrichment and separation of PAEs as an SPE filler [21-23].

In this paper, an economical resin-based COF material was prepared. The adsorption properties of the materials were studied by adsorption experiments, and the SPE separation ability of four phthalate esters (DMP, DEP, DBP, DOP) in water samples was investigated. At the same time, the solid phase extraction effect between the two COFfilled SPE columns and the commercial SPE columns was detected by High performance liquid chromatography (HPLC). The results demonstrated that this new COF material could provide a theoretical basis for the detection and enrichment of phthalate esters in practical samples.

\section{Materials and Methods}

\subsection{Reagents and Instruments}

Dimethyl phthalate (DMP), diethyl phthalate (DEP), dibutyl phthalate (DBP), and dioctyl phthalate (DOP) were obtained from Aladdin (Shanghai, China); methanol, acetic acid, and ethanol were obtained from Sinopharm Chemical Reagent Co., Ltd. (Shanghai, China). All of the above reagents were analytically pure. Strata- $X$, Strata-X-CW, Strata-X-C, and Strata-X-A were obtained from Phenomenex (Tianjin, China).

LC-10AT high performance liquid chromatograph was obtained from Shimadzu Co., Ltd. (Shanghai, China).

\subsection{Experimental Methods}

\subsubsection{Preparation of COF Materials}

TpBD COFs and resin-based COFs' preparation methods and their morphologies, functional groups, thermal stability, structural characteristics, and pore structure are referred to in $[24,25]$.

\subsubsection{Determination of PAEs Adsorption Behavior}

WE accurately weighed a certain volume of DMP and added it into the volumetric flask, then prepared the solution according to the ratio of acetonitrile:water $=9: 1$, and finally prepared dimethyl phthalate solution with concentrations of $2,4,6,8$, and $10 \mathrm{~mL} / \mathrm{L}$, respectively. DEP, DBP and DOP standard solution were also prepared according to the above methods. In the adsorption experiment, the volume of DMP, DEP, DBP, and DOP was $100 \mathrm{~mL}$ (molar ratio: 6:5:4:3, respectively), and the adsorption time was $20 \mathrm{~min}$.

Mobile phase: $\mathrm{v}$ (acetonitrile): $\mathrm{v}\left(\mathrm{H}_{2} \mathrm{O}\right)=90: 10$; The column temperature was $35^{\circ} \mathrm{C}$; Chromatographic column: specification: $4.6 \mathrm{~mm} \times 10 \mathrm{~mm}$, the fillers were TpBD COFs and resin based COFs, respectively; The flow rate was $1 \mathrm{~mL} / \mathrm{min}$; UV detector detection; The detection wavelength was $295 \mathrm{~nm}$ (Figure S1); Washed the chromatographic column with mobile phase and run for $30 \mathrm{~min}$ to fill the reference cell with mobile phase until the baseline was stable. Then, the concentration of the sample solution to be measured was sucked into the chromatographic column by the pump from low to high for measurement, and the suction time of the sample was recorded. When the response value of the outflow curve of the sample in the column did not increase, changed another sample until all the samples were tested, and recorded the midpoint time of all the penetration curves. Then, we washed the column with mobile phase and saturate the column with pure acetonitrile. The specific methods for analyzing the adsorption behavior of materials by the frontal analysis method can be referred to the literature [26,27].

\subsubsection{SPE Experiment}

Since the SPE effect of this experiment was compared with that of the commercial SPE filler columns, the filling conditions of this experiment were the same as that of the commercial SPE filler columns when assembling the SPE filler columns. The specific 
parameters were as follows: the mass of SPE filler of TpBD COFs and resin-based COFs material were $100 \mathrm{mg}$; the volume of extraction columns was $10 \mathrm{~mL}$; and during activation, load, washing, and elution, the flow rate in the elution step was $1 \mathrm{~mL} / \mathrm{min}$. Samples were taken from commercial water and vitamin beverages in plastic containers. The standard samples of four phthalate esters were obtained by dissolving DMP, DEP, DBP, and DOP in acetonitrile solution. The HPLC analysis conditions are as follows:

The wavelength and mobile phase were the same as above. Chromatographic analysis was performed on an Agilent XDB-C18 $(4.6 \mathrm{~mm} \times 250 \mathrm{~mm}, 5 \mu \mathrm{m})$ column.

We added TpBD COFs or resin-based COFs into the empty column tube of solid phase extraction with gaskets, respectively. After paving, we pressed another gasket gently on the materials to assemble the COF-filled SPE column. The commercial SPE columns as the control are four different types of SPE columns. The schemes are shown in Figure 1.

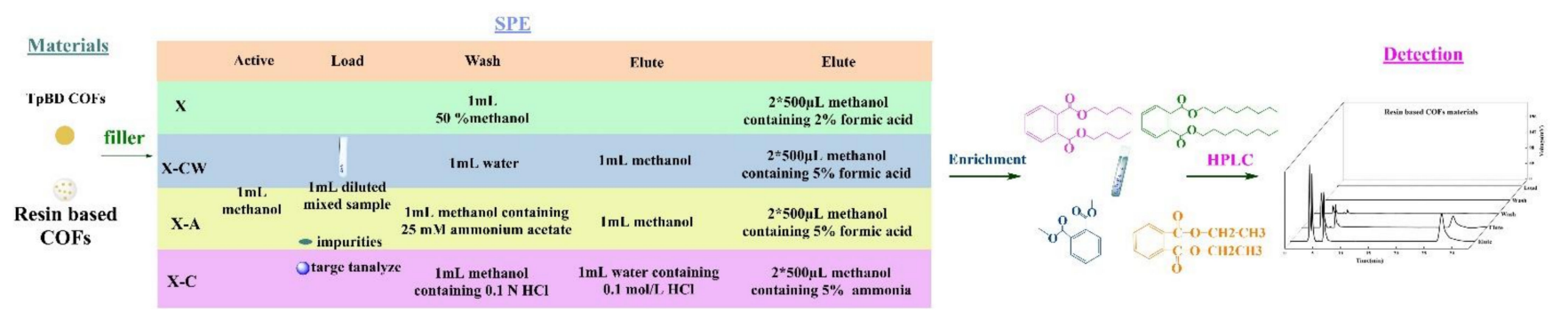

Figure 1. SPE flow chart.

\subsubsection{Stability Experiment of Four PAEs}

We made a determination of the PAEs mixture every half hour, with a precise injection of a $20 \mu \mathrm{L}$ sample each time. The standard deviation (SD) and relative standard deviation (RSD) was calculated according to the following formula.

\subsubsection{Precision Analysis of Four PAEs}

Four PAEs mixed solutions were selected, and the mixed solutions were measured in parallel for five times in a day, with $20 \mu \mathrm{L}$ samples injected each time. The SD and RSD was calculated according to the following formula.

$$
\begin{gathered}
\mathrm{SD}=\sqrt{\frac{1}{\mathrm{~N}-1} \sum_{\mathrm{i}=1}^{\mathrm{N}}\left(\mathrm{X}_{i}-\overline{\mathrm{X}}\right)^{2}} \\
\mathrm{RSD}=\frac{\mathrm{SD}}{\overline{\mathrm{X}}} \times 100 \%
\end{gathered}
$$

\subsubsection{Recovery of Four PAEs}

SPE experiments were carried out for the mixed solution and the spiked mixed solution according to the X-A and X-C methods, respectively. The recovered SPE solution obtained was analyzed and determined by HPLC. Each sample was injected $20 \mu \mathrm{L}$, and each recovered liquid sample was tested three times in parallel. The average peak area was used to calculate the recovery rate and average recovery rate.

\subsubsection{Repetitive Experiment of Four PAEs}

In order to investigate the reusability of the materials, the self-made COFs materials filler column was repeated for 50 times of SPE experiment, and the collected SPE recovery solution was determined. Taking the HPLC test results as the evaluation standard, the reusability effects of COFs and resin-based COFs materials were compared. 


\section{Results}

\subsection{Adsorption Behavior of Materials}

\subsubsection{Analysis of Adsorption Effect of COFS on PAEs}

By observing the relationship between the concentration and adsorption of dimethyl phthalate, diethyl phthalate, dibutyl phthalate, and dioctyl phthalate (Figure 2), it could be seen that the adsorption capacity of PAEs increased with the increase of concentration, the reason was that the effect of surface adsorbed solute migration to the interior of the material was caused by the synergistic effect of solute re adsorption. The adsorption effect, adsorption capacity, and retention time of substances were as follows: resin-based COFs $<$ TpBD COFs. It could be seen that the new resin-based COFs had better adsorption performance. When comparing the PAEs concentration and retention time (Table 1), it could be seen that the greater the concentration of the PAEs, the shorter the retention time. The reason for this analysis was that when the PAEs concentration was high, the solute content was higher; the faster the binding adsorption with the materials, the shorter the retention time.
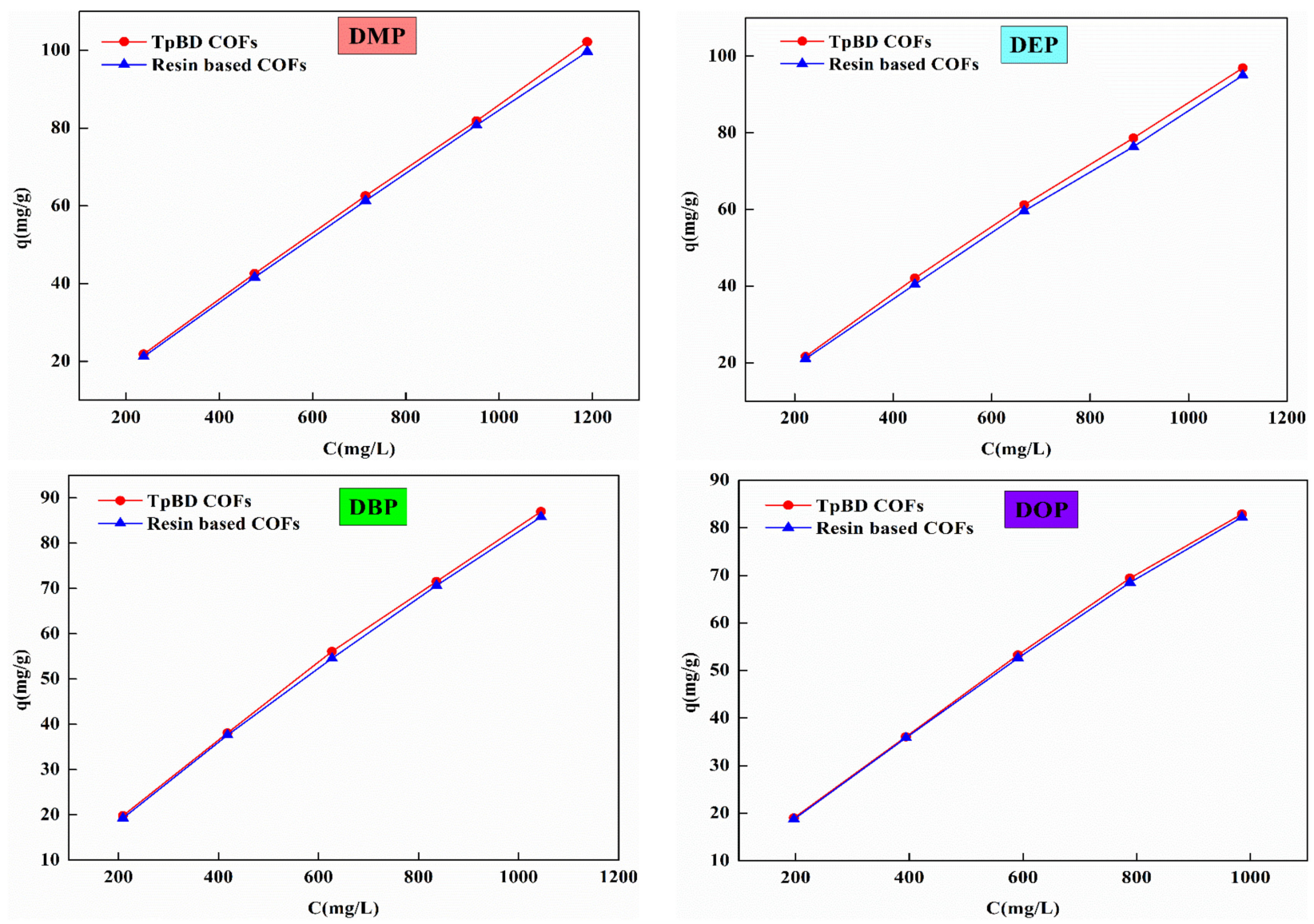

Figure 2. Adsorption curve of PAEs.

Table 1. Retention time of material to substance.

\begin{tabular}{cccccc}
\hline & $\mathbf{c}\left(\mathbf{m g ~ L}^{-1}\right)$ & $\mathbf{t}_{\text {RDMP }}(\mathbf{m i n})$ & $\mathbf{t}_{\text {RDEP }}(\mathbf{m i n})$ & $\mathbf{t}_{\text {RDBP }}(\mathbf{m i n})$ & $\mathbf{t}_{\text {RDOP }}(\mathbf{m i n})$ \\
\hline & 237.8 & 9.205 & 9.751 & 9.485 & 9.648 \\
TpBD COFs & 475.6 & 8.951 & 9.482 & 9.113 & 9.156 \\
& 713.4 & 8.769 & 9.189 & 8.947 & 9.012 \\
& 951.5 & 8.603 & 8.859 & 8.558 & 8.809 \\
& 1189 & 8.595 & 8.734 & 8.325 & 8.415 \\
\hline
\end{tabular}


Table 1. Cont.

\begin{tabular}{cccccc}
\hline & $\mathbf{c}\left(\mathbf{m g ~ L}^{-\mathbf{1}}\right)$ & $\mathbf{t}_{\text {RDMP }}(\mathbf{m i n})$ & $\mathbf{t}_{\text {RDEP }}(\mathbf{m i n})$ & $\mathbf{t}_{\text {RDBP }}(\mathbf{m i n})$ & $\mathbf{t}_{\text {RDOP }}(\mathbf{m i n})$ \\
\hline & 237.8 & 8.925 & 9.485 & 9.225 & 9.501 \\
Resin based & 475.6 & 8.751 & 9.113 & 8.999 & 9.098 \\
COFs & 713.4 & 8.595 & 8.951 & 8.702 & 8.901 \\
& 951.5 & 8.485 & 8.603 & 8.452 & 8.691 \\
& 1189 & 8.382 & 8.558 & 8.21 & 8.348 \\
\hline
\end{tabular}

$\left(\mathrm{t}_{\mathrm{R}}\right.$ is the retention time).

\subsubsection{Static Adsorption Behavior of PAEs by COFs}

In the comparison of Table 2, it could be found that the fitting correlation coefficient of the Fredunlich model was larger than that of the Langmuir model. Therefore, it was considered that the isothermal adsorption process of PAEs adsorbed by the two materials was more in line with Fredunlich isothermal adsorption model.

Table 2. Static parameters of PAEs.

\begin{tabular}{|c|c|c|c|c|c|c|c|c|c|}
\hline \multirow[b]{2}{*}{ Material } & \multirow[b]{2}{*}{ Analyte } & \multicolumn{4}{|c|}{$\frac{\mathrm{C}_{\mathrm{e}}}{\mathrm{q}_{\mathrm{e}}}=\frac{1}{\mathrm{q}_{\mathrm{m}} \mathrm{K}_{\mathrm{L}}}+\frac{\mathrm{C}_{\mathrm{e}}}{\mathrm{q}_{\mathrm{m}}}$} & \multicolumn{4}{|c|}{$\lg q_{e}=\lg k+\frac{1}{n} \lg C_{e}$} \\
\hline & & Linear Formula & $\mathbf{R}^{2}$ & $\underset{\left(m g \cdot g^{-1}\right)}{q_{m}}$ & $\begin{array}{c}\mathrm{K}_{\mathrm{L}} \\
\left(\times 10^{-5}\right)\end{array}$ & Linear Formula & $\mathbf{R}^{2}$ & $\mathbf{n}$ & $\mathbf{K}_{\mathbf{F}}$ \\
\hline \multirow{4}{*}{$\begin{array}{l}\text { TpBD } \\
\text { COFs }\end{array}$} & DMP & $y=0.000838 x+10.741$ & 0.909 & 1193.32 & 7.802 & $y=0.954 x-0.928$ & 0.999 & 1.048 & 0.118 \\
\hline & DEP & $y=0.00141 x+9.945$ & 0.983 & 709.22 & 1.417 & $y=0.929 x-0.841$ & 0.999 & 1.076 & 0.144 \\
\hline & DBP & $y=0.00175 x+10.183$ & 0.984 & 571.43 & 1.178 & $y=0.921 x-0.837$ & 0.999 & 1.085 & 0.145 \\
\hline & DOP & $y=0.00176 x+10.083$ & 0.952 & 568.18 & 1.745 & $y=0.923 x-0.837$ & 0.999 & 1.083 & 0.145 \\
\hline \multirow{4}{*}{$\begin{array}{l}\text { Resin } \\
\text { based } \\
\text { COFs }\end{array}$} & DMP & $y=0.000761 x+11.053$ & 0.986 & 1314.06 & 6.885 & $y=0.961 x-0.955$ & 0.999 & 1.045 & 0.111 \\
\hline & DEP & $y=0.00132 x+10.319$ & 0.944 & 757.58 & 1.279 & $y=0.934 x-0.867$ & 0.999 & 1.071 & 0.136 \\
\hline & DBP & $y=0.00163 x+10.471$ & 0.997 & 613.50 & 1.556 & $y=0.928 x-0.864$ & 0.999 & 1.077 & 0.136 \\
\hline & DOP & $y=0.00174 x+10.219$ & 0.979 & 574.71 & 1.702 & $y=0.925 x-0.848$ & 0.999 & 1.081 & 0.141 \\
\hline
\end{tabular}

Since the Langmuir model is more suitable for the situation that the adsorbent surface is uniform, there is no interaction between adsorbates, and the adsorption is monolayer adsorption. In other words, the adsorption only occurs on the outer surface of the adsorbent, and the assumption of the model is sensitive to the changes of experimental conditions. As an empirical adsorption isothermal equation suitable for heterogeneous surface adsorption, the Fredunlich adsorption isothermal model can not only well describe the adsorption mechanism of heterogeneous surface, but also be more suitable for low concentration adsorption. It could well explain the experimental results in a wider concentration range. As an adsorption material with a porous structure, the surface of COF materials was mostly porous in terms of structure. The adsorption behavior was also more diversified, which is consistent with the fitting of isothermal adsorption model and the action mechanism of the Fredunlich isothermal adsorption model. This was consistent with the conclusion of quasi second-order dynamics.

\subsubsection{Kinetic Adsorption Behavior of PAEs by COFs}

It could be seen from Table 3 that because the fitting parameter $\mathrm{R}^{2}$ of the quasi secondorder kinetic model was higher than that of the quasi first-order kinetic model. This proved that the kinetic adsorption behavior of COF materials on PAEs conformed to the quasi second-order kinetic model, and it also showed that the adsorption process of COF materials on PAEs was not determined by physical adsorption under a single force. This was the result of surface adsorption combined with internal pore steric resistance and liquid film resistance. 
Table 3. Kinetic parameters of PAEs.

\begin{tabular}{|c|c|c|c|c|c|c|c|}
\hline \multirow[b]{2}{*}{ Material } & \multirow[b]{2}{*}{ Analyte } & \multicolumn{3}{|c|}{$\ln \left(q_{e}-q_{t}\right)=\ln q_{e}-K_{1} t$} & \multicolumn{3}{|c|}{$1 /\left(\mathbf{q}_{\mathrm{e}}-\mathbf{q}_{\mathbf{t}}\right)=1 / \mathbf{q}_{\mathrm{e}}+\mathbf{K}_{2} \mathbf{t}$} \\
\hline & & Linear Formula & $\mathbf{R}^{2}$ & $K_{1} /\left(1 \min ^{-1}\right)$ & Linear Formula & $\mathbf{R}^{2}$ & $\begin{array}{c}\mathrm{K}_{2} \\
\left(10^{-3} \cdot \mathrm{g} /(\mathrm{mg} \cdot \mathrm{min})\right)\end{array}$ \\
\hline & DMP & $y=-0.315 x+5.506$ & 0.696 & 0.315 & $\mathrm{y}=0.0272 \mathrm{x}-0.157$ & 0.963 & 0.027 \\
\hline $\mathrm{TpBD}$ & DEP & $y=-0.253 x+5.169$ & 0.790 & 0.253 & $y=0.0169 x-0.0886$ & 0.975 & 0.0170 \\
\hline \multirow{3}{*}{ COFs } & DBP & $\mathrm{y}=-0.275 \mathrm{x}+5.129$ & 0.754 & 0.275 & $\mathrm{y}=0.0219 \mathrm{x}-0.113$ & 0.964 & 0.022 \\
\hline & DOP & $y=-0.247 x+4.901$ & 0.775 & 0.247 & $\mathrm{y}=0.0184 \mathrm{x}-0.0855$ & 0.981 & 0.018 \\
\hline & DMP & $y=-0.300 x+5.357$ & 0.718 & 0.300 & $\mathrm{y}=0.0239 \mathrm{x}-0.129$ & 0.980 & 0.024 \\
\hline \multirow{3}{*}{$\begin{array}{l}\text { Resin based } \\
\text { COFs }\end{array}$} & DEP & $y=-0.259 x+5.103$ & 0.782 & 0.259 & $y=0.0179 x-0.0882$ & 0.968 & 0.018 \\
\hline & DBP & $y=-0.275 x+5.101$ & 0.754 & 0.275 & $y=0.0220 x-0.111$ & 0.971 & 0.022 \\
\hline & DOP & $\mathrm{y}=-0.262 \mathrm{x}+4.959$ & 0.749 & 0.262 & $\mathrm{y}=0.0211 \mathrm{x}-0.102$ & 0.987 & 0.021 \\
\hline
\end{tabular}

\subsection{Evaluation of SPE Performance}

\subsubsection{Analysis of Detection Conditions of PAEs by HPLC}

Figure 3 shows the HPLC outflow curves of four PAEs under different proportions of mobile phase (acetonitrile:water $/ v / v$ ) and different elution flow rates. When determining the best separation conditions for the four substances, it was found that the separation effect was not ideal when acetonitrile:water $=94: 6(v / v)$ and 92:8 $(v / v)$. When acetonitrile:water $=88: 12(v / v)$ and 85:15 $(v / v)$, the effect was better, but the experimental time was long and there would be interfering peaks. Therefore, acetonitrile:water $=90: 10(v / v)$ was selected as the mobile phase ratio for the analysis of four phthalate esters. When selecting the eluting velocity, it can be found that when the flow rate is $0.8 \mathrm{~mL} \mathrm{~min}^{-1}$, the chromatographic outflow curve not only took a long time, but also had interfering peaks. Therefore, a flow rate of

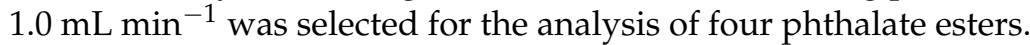
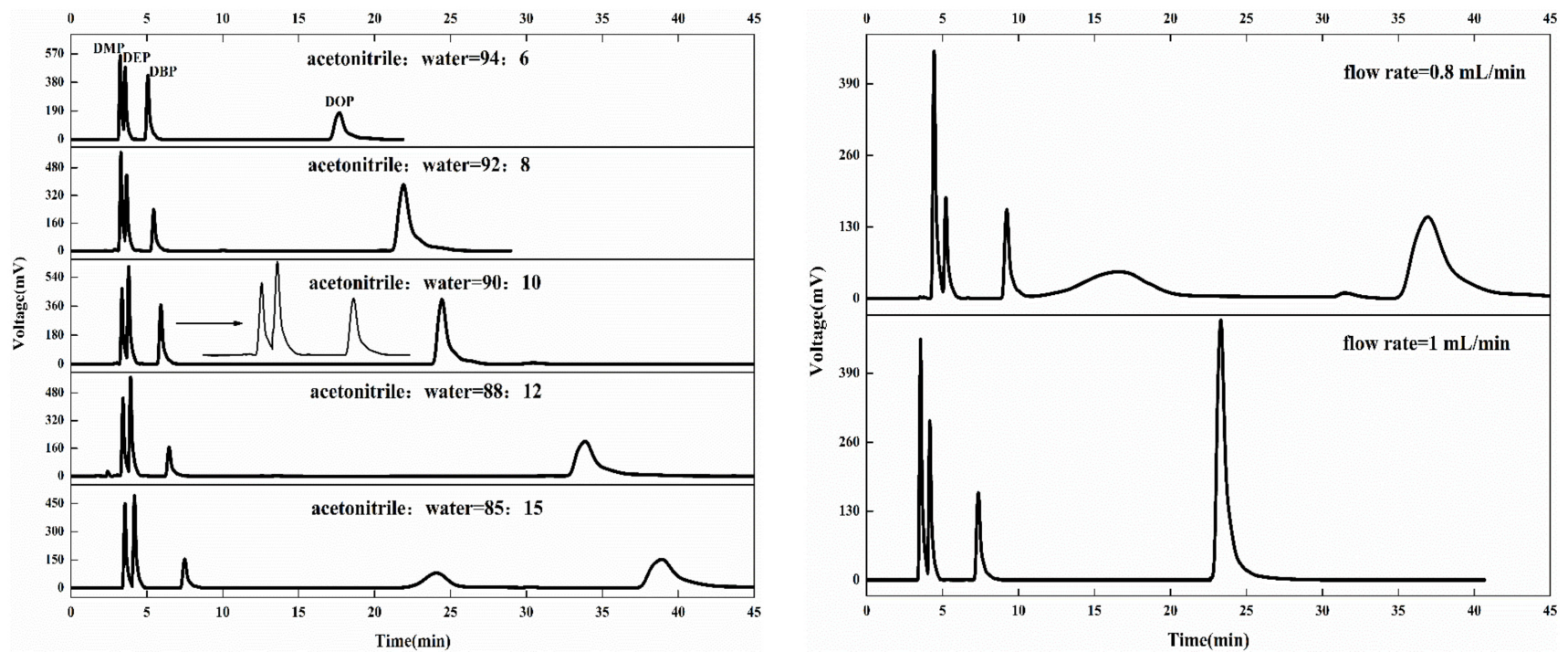

Figure 3. Effect of different mobile phase ratio and flow rate on PAEs separation effect.

\subsubsection{Determination of Standard Curve of PAEs}

After determining the analytical conditions of PAEs by HPLC, the linear relationship and detection limit of this method were investigated. Figure 4 shows the standard curve of mixed substances. Table 4 lists the linear equations of four PAEs. It was found that the method reported in this paper had a good linear relationship for the detection of PAEs, indicating that this method was suitable for the trace detection requirements of PAEs. 


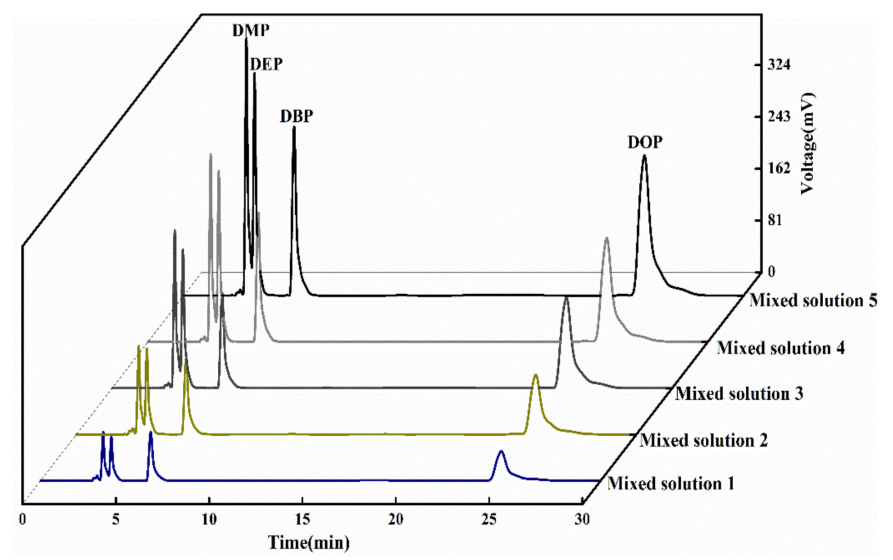

Figure 4. Standard curve of mixed substances.

Table 4. Detection limit of PAEs.

\begin{tabular}{ccccc}
\hline PAEs & Linear Equation & $\mathbf{R}^{\mathbf{2}}$ & LOD $(\boldsymbol{\mu g} / \mathbf{L})$ & RSD $(\%) \mathbf{n}=\mathbf{5}$ \\
\hline DMP & $\mathrm{y}=8.64 \times 10^{7} \times \mathrm{x}-7.14 \times 10^{4}$ & 0.997 & 0.02 & 0.118 \\
DEP & $\mathrm{y}=8.39 \times 10^{7} \times \mathrm{x}+8.65 \times 10^{3}$ & 0.992 & 0.05 & 0.149 \\
DBP & $\mathrm{y}=8.26 \times 10^{7} \times \mathrm{x}+3.84 \times 10^{5}$ & 0.996 & 0.01 & 0.127 \\
DOP & $\mathrm{y}=2.13 \times 10^{8} \times \mathrm{x}+2.75 \times 10^{5}$ & 0.991 & 0.06 & 0.306 \\
\hline
\end{tabular}

\subsubsection{Evaluation of the Effect of PAEs SPE Materials}

In order to evaluate the SPE effect of prepared COFs on PAEs and compare it with the results in reported articles, Table 5 shows the analysis of the results of enrichment of PAEs by SPE reported in the literature in recent years. It could be seen from Table 6 that the two COF materials prepared in this paper were used as fillers to enrich and separate PAEs by solid phase extraction. The sample recovery was better than other adsorbents, and this method was simple to operate.

Table 5. Comparison with the reported PAEs determination method [21-25].

\begin{tabular}{|c|c|c|c|c|c|}
\hline Sorbent & Method & Sample & Elution Solution & Recovery & Ref \\
\hline GO@LDH@SPAN & GC-MS & water and beverage & methanol & $54.5-112.6 \%$ & [28] \\
\hline Nanofiber pad & SPE-HPLC & $\begin{array}{l}\text { tap water, rainwater } \\
\text { and pool water }\end{array}$ & acetonitrile, methanol & $>88 \%$ & [29] \\
\hline polysulfone hollow fiber & SPME-FE/GC & water & ethanol & $87.0-117.7 \%$ & [30] \\
\hline $\mathrm{CuFe}_{2} \mathrm{O}_{4}$ Nanoparticles & SPME & water & water & $81.1-103.7 \%$ & [31] \\
\hline Graphene modified COF & HS-SPME-GC-MS & water & $10 \%(w / v)$ salt & $80.5-111.0 \%$ & [32] \\
\hline $\begin{array}{c}\text { TpBD COFs } \\
\text { Resin based COFs }\end{array}$ & SPE-HPLC & water and beverage & methanol & $\begin{array}{c}98.26-100.56 \% \\
97.99-99.30 \%\end{array}$ & This work \\
\hline
\end{tabular}

\subsubsection{Analysis of SPE Scheme for PAEs}

Figures 5-8 are the chromatographic outflow curves of four PAEs according to the solid phase extraction scheme described in Table 6. Through comparison, the SPE effect of model X and X-CW schemes were: TpBD filler SPE column > commercial extraction column $>$ resin-based COF material filler SPE column. When X-A and X-C schemes were adopted, the SPE effects were: resin-based COF material filler SPE column $\approx$ TpBD filler SPE column > commercial extraction column. Therefore, when resin-based COF material was used as SPE filler, the enrichment effect of phthalate esters was better when X-A and $\mathrm{X}-\mathrm{C}$ schemes were adopted (The acid-base free $\mathrm{X}-\mathrm{C}$ solid phase extraction scheme is shown in Figure S2). Taking this as the evaluation standard, the extraction effects of the four SPE schemes were as follows: $\mathrm{X}-\mathrm{C}>\mathrm{X}-\mathrm{A}>\mathrm{X}>\mathrm{X}-\mathrm{CW}$. The recovery rates of PAEs of the three materials used as SPE fillers were further analyzed in the experiment (Table 6). The analysis found that SPE effect was consistent with the above conclusion. Therefore, it could be 
concluded that during SPE experiment. The results showed that the solid phase extraction effect of TpBD COFs was better than that of commercially available materials and resin based COFs when X and X-CW schemes were used, and the SPE effect of resin based COFs was better than that of commercially available materials and TpBD COFs when X-A and $\mathrm{X}$-C schemes were used. It also proved that the self-made materials had better solid phase extraction performance as solid phase extraction fillers.

Table 6. Recovery of different SPE schemes.

\begin{tabular}{|c|c|c|c|c|c|c|c|}
\hline Sample & Method & Material & $\begin{array}{l}\text { Recovery } \\
(\%, n=3)\end{array}$ & Material & $\begin{array}{l}\text { Recovery } \\
(\%, n=3)\end{array}$ & Material & $\begin{array}{l}\text { Recovery } \\
(\%, n=3)\end{array}$ \\
\hline \multirow{4}{*}{ DMP } & $x$ & \multirow{16}{*}{ Market } & 89.69 & \multirow{16}{*}{ TpBD COFs } & 93.51 & & 70.23 \\
\hline & $\mathrm{X}-\mathrm{CW}$ & & 70.62 & & 99.23 & & 62.46 \\
\hline & X-A & & 80.56 & & 90.38 & & 99.21 \\
\hline & $\mathrm{X}-\mathrm{C}$ & & 62.31 & & 90.56 & & 99.99 \\
\hline \multirow{5}{*}{ DEP } & $x$ & & 86.71 & & 92.87 & & 69.13 \\
\hline & X-CW & & 68.75 & & 99.99 & & 60.35 \\
\hline & $X-A$ & & 82.56 & & 92.51 & & 99.23 \\
\hline & $\mathrm{X}-\mathrm{C}$ & & 68.89 & & 91.88 & Resin based & 99.87 \\
\hline & $x$ & & 85.99 & & 94.62 & $\mathrm{COFs}$ & 75.78 \\
\hline \multirow{3}{*}{ DBP } & $\mathrm{X}-\mathrm{CW}$ & & 60.23 & & 97.80 & & 59.12 \\
\hline & X-A & & 86.89 & & 92.61 & & 96.56 \\
\hline & $X-C$ & & 65.26 & & 91.10 & & 95.30 \\
\hline \multirow{4}{*}{ DOP } & $x$ & & 59.56 & & 90.83 & & 80.89 \\
\hline & X-CW & & 30.25 & & 78.92 & & 98.73 \\
\hline & X-A & & 83.45 & & 98.99 & & 96.18 \\
\hline & $X-C$ & & 30.23 & & 98.00 & & 92.89 \\
\hline
\end{tabular}
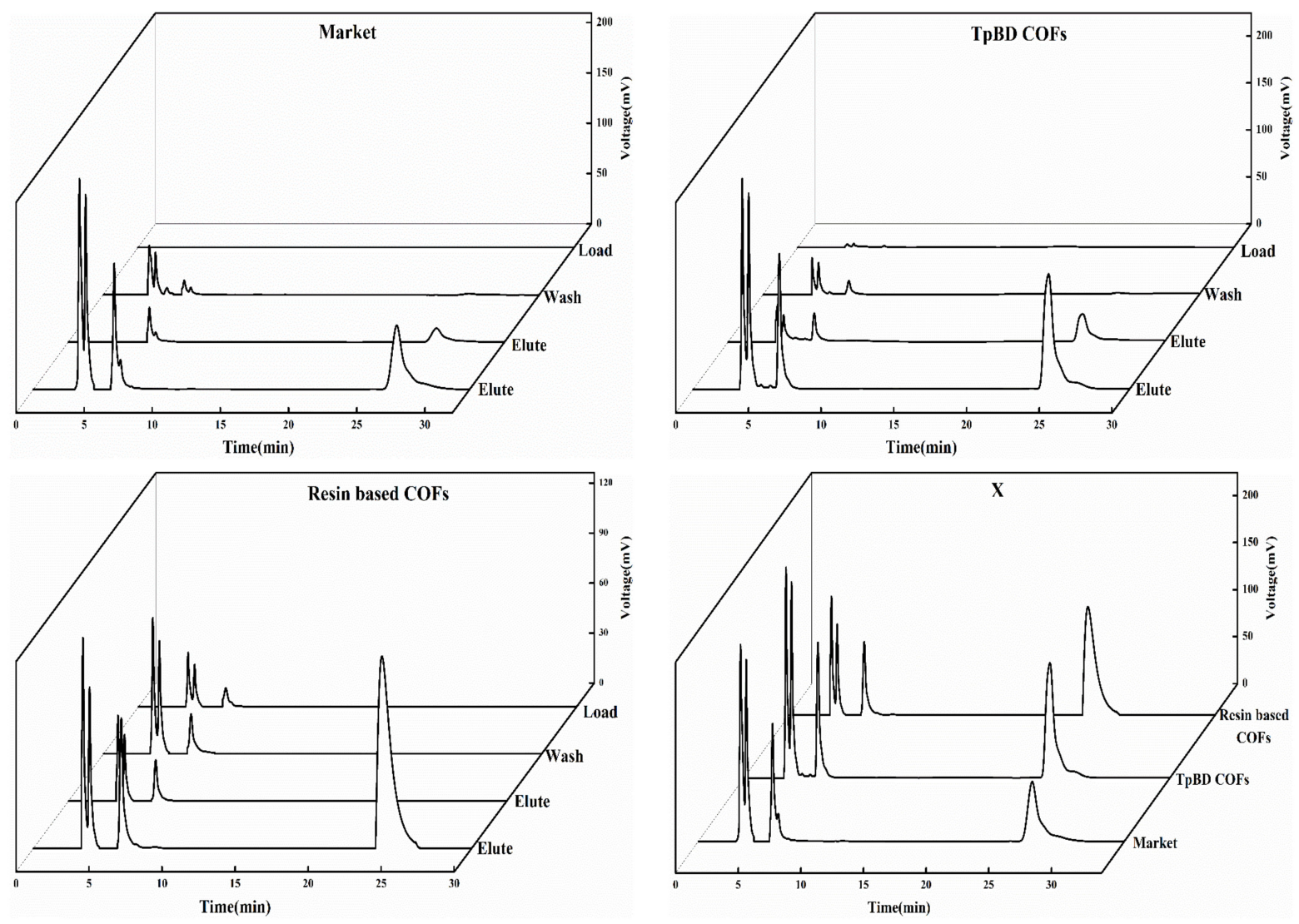

Figure 5. Outflow curves using the $X$ method. 

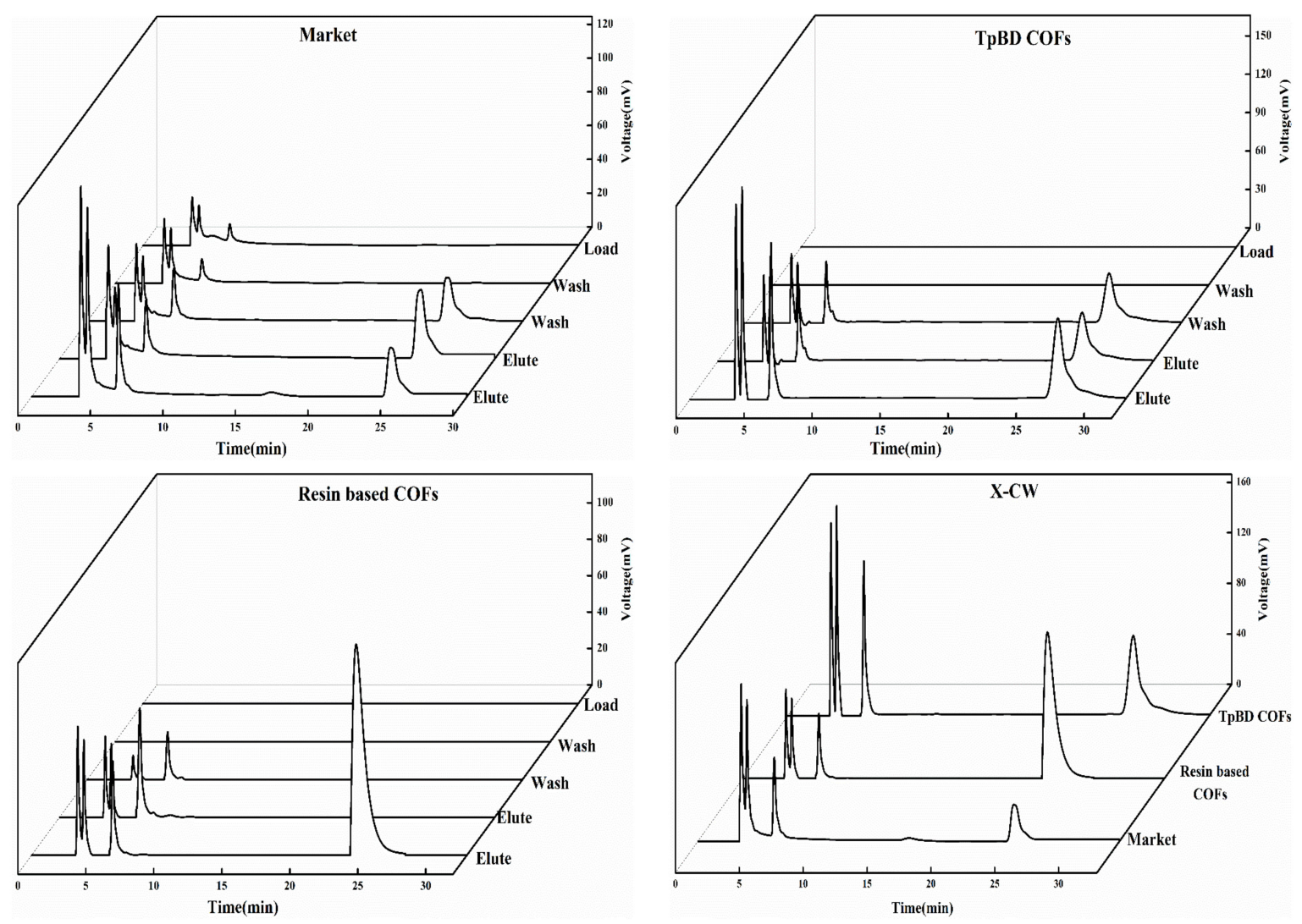

Figure 6. Outflow curves using the X-CW method.
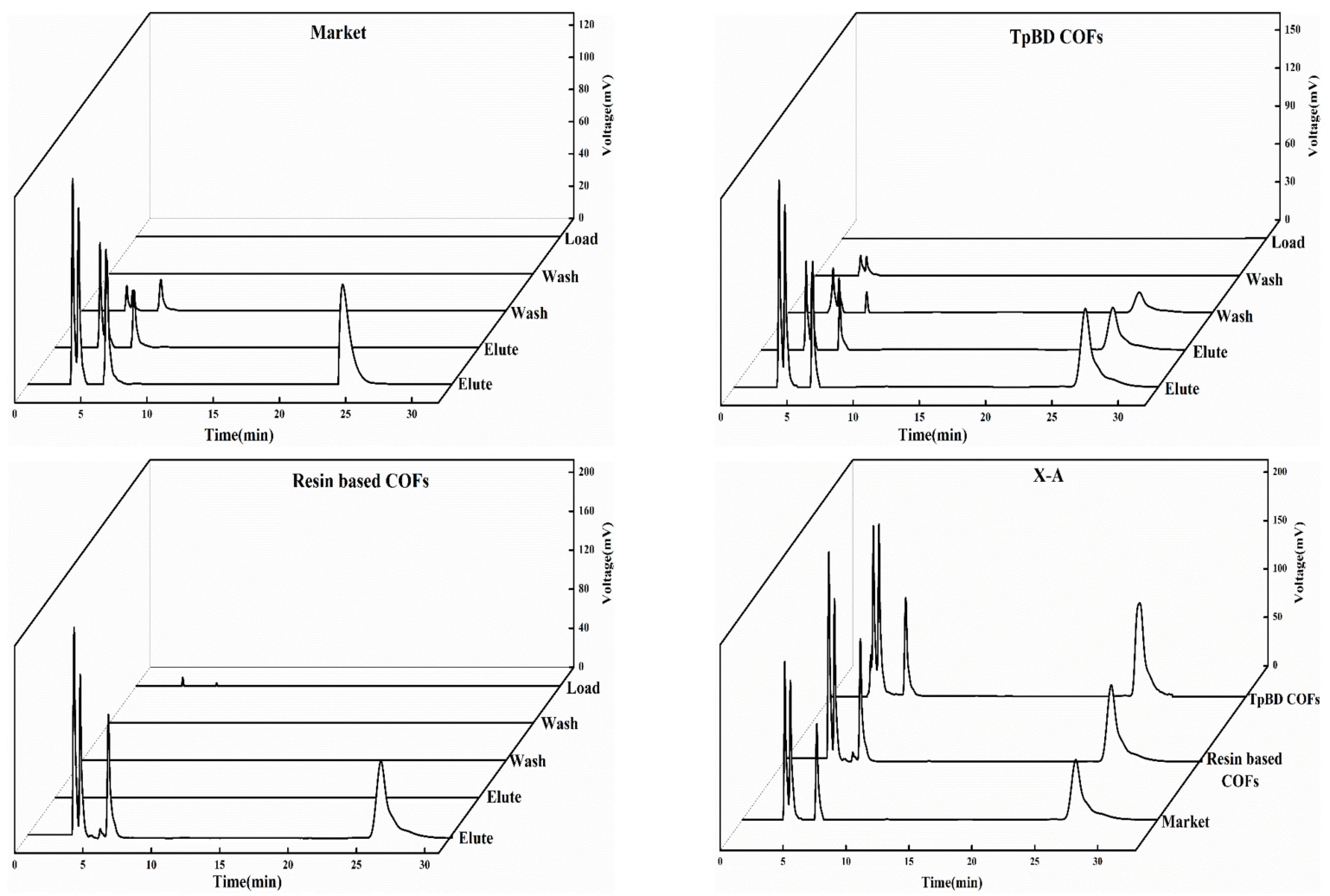

Figure 7. Outflow curves using the X-A method. 

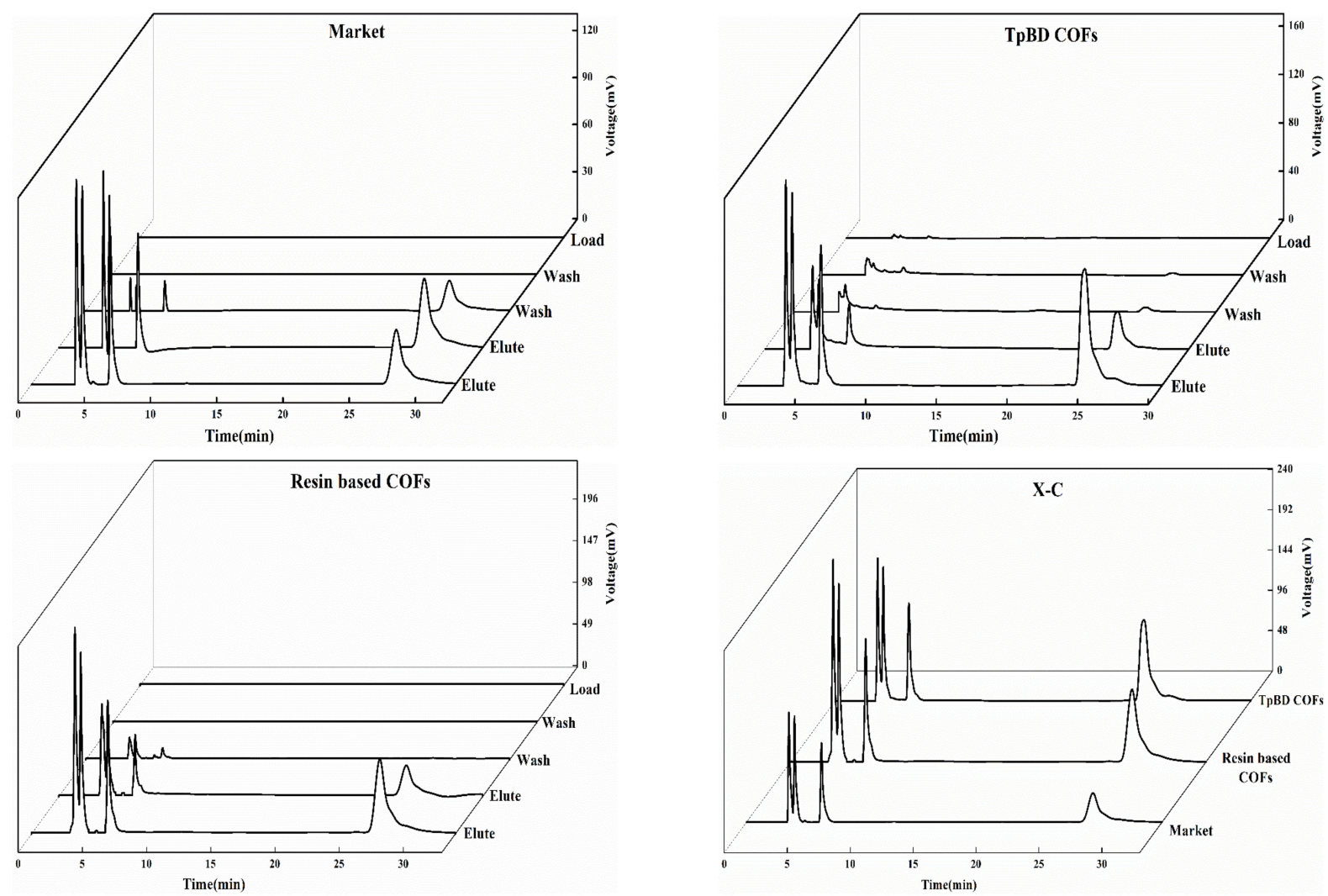

Figure 8. Outflow curves using the $\mathrm{X}-\mathrm{C}$ method.

\subsubsection{Stability Analysis of Four PAEs}

In order to study the enrichment and separation effects of $\mathrm{X}-\mathrm{A}$ and $\mathrm{X}-\mathrm{C}$ solid phase extraction schemes on PAEs, the stability of four PAEs under different solid phase extraction schemes was analyzed. It could be seen from Table 7 that under the same conditions, the five measured values of the same sample are relatively close, and the RSD of the two methods are less than $2 \%$, which proves that the chromatographic conditions of this experiment were used to detect four PAEs with good stability.

Table 7. Results of SPE of four kinds of PAEs.

\begin{tabular}{|c|c|c|c|c|c|c|c|c|c|c|}
\hline \multirow[t]{2}{*}{ Analyte } & \multirow[t]{2}{*}{ Method } & \multicolumn{6}{|c|}{ Peak Area $\left(\times 10^{6}\right)$} & \multirow{2}{*}{$\begin{array}{c}\text { Average }\left(\times \mathbf{1 0}^{\mathbf{6}}\right) \\
2.164\end{array}$} & \multirow{2}{*}{$\begin{array}{c}\text { SD }\left(\times \mathbf{1 0}^{\mathbf{6}}\right) \\
0.0114\end{array}$} & \multirow{2}{*}{$\begin{array}{c}\text { RSD (\%) } \\
0.526\end{array}$} \\
\hline & & DMP & 2.18 & 2.17 & 2.15 & 2.16 & 2.16 & & & \\
\hline \multirow{7}{*}{ Mixture1 } & \multirow{3}{*}{$X-A$} & DEP & 2.16 & 2.16 & 2.16 & 2.14 & 2.15 & 2.154 & 0.00894 & 0.415 \\
\hline & & DBP & 1.47 & 1.46 & 1.49 & 1.46 & 1.46 & 1.468 & 0.0130 & 0.888 \\
\hline & & DOP & 1.39 & 1.40 & 1.38 & 1.39 & 1.40 & 1.392 & 0.00836 & 0.601 \\
\hline & \multirow{5}{*}{$\mathrm{X}-\mathrm{C}$} & DMP & 2.34 & 2.36 & 2.32 & 2.34 & 2.35 & 2.342 & 0.0148 & 0.633 \\
\hline & & DEP & 2.18 & 2.18 & 2.18 & 2.17 & 2.17 & 2.176 & 0.00547 & 0.251 \\
\hline & & DBP & 1.48 & 1.47 & 1.5 & 1.47 & 1.46 & 1.476 & 0.0151 & 1.027 \\
\hline & & DOP & 1.42 & 1.42 & 1.42 & 1.40 & 1.40 & 1.412 & 0.0109 & 0.775 \\
\hline \multirow{8}{*}{ Mixture2 } & & DMP & 3.99 & 3.99 & 4.02 & 4.00 & 3.98 & 3.996 & 0.0151 & 0.379 \\
\hline & \multirow{3}{*}{$X-A$} & DEP & 3.32 & 3.32 & 3.34 & 3.33 & 3.32 & 3.326 & 0.00894 & 0.268 \\
\hline & & DBP & 2.61 & 2.60 & 2.60 & 2.60 & 2.60 & 2.602 & 0.00447 & 0.171 \\
\hline & & DOP & 1.92 & 1.90 & 1.93 & 1.91 & 1.90 & 1.912 & 0.0130 & 0.681 \\
\hline & \multirow{4}{*}{$\mathrm{X}-\mathrm{C}$} & DMP & 4.85 & 4.83 & 4.86 & 4.82 & 4.82 & 4.836 & 0.0181 & 0.375 \\
\hline & & DEP & 2.92 & 2.92 & 2.90 & 2.90 & 2.91 & 2.910 & 0.010 & 0.343 \\
\hline & & DBP & 2.88 & 2.9 & 2.87 & 2.89 & 2.87 & 2.882 & 0.0130 & 0.452 \\
\hline & & DOP & 2.23 & 2.23 & 2.21 & 2.22 & 2.23 & 2.224 & 0.00894 & 0.402 \\
\hline
\end{tabular}




\subsubsection{Precision Analysis of Four PAEs}

In order to investigate the enrichment and separation effect of $\mathrm{X}-\mathrm{A}$ and $\mathrm{X}-\mathrm{C}$ solid phase extraction schemes on PAEs, the separation precision of four PAEs under different SPE schemes was analyzed. It could be seen from Table 8 that under the same conditions, the five measured values of the same sample were relatively close, and the RSD of the two methods were less than $5 \%$, that was, the chromatographic conditions of this experiment were used to detect four phthalate esters with good accuracy.

Table 8. Results of SPE of four kinds of PAEs.

\begin{tabular}{|c|c|c|c|c|c|c|c|c|c|c|}
\hline \multirow[t]{2}{*}{ Analyte } & \multirow[t]{2}{*}{ Method } & \multicolumn{6}{|c|}{ Peak Area $\left(\times 10^{6}\right)$} & \multirow{2}{*}{$\begin{array}{c}\text { Average }\left(\times \mathbf{1 0}^{\mathbf{6}}\right) \\
2.298\end{array}$} & \multirow{2}{*}{$\frac{\mathrm{SD}\left(\times \mathbf{1 0}^{\mathbf{6}}\right)}{0.0303}$} & \multirow{2}{*}{$\begin{array}{c}\text { RSD (\%) } \\
1.31\end{array}$} \\
\hline & & DMP & 2.28 & 2.26 & 2.31 & 2.30 & 2.34 & & & \\
\hline \multirow{7}{*}{ Mixture1 } & \multirow{3}{*}{$X-A$} & DEP & 2.17 & 2.18 & 2.18 & 2.20 & 2.19 & 2.184 & 0.0114 & 0.52 \\
\hline & & DBP & 1.49 & 1.42 & 1.58 & 1.56 & 1.46 & 1.502 & 0.0672 & 2.47 \\
\hline & & DOP & 1.42 & 1.44 & 1.48 & 1.39 & 1.50 & 1.446 & 0.0444 & 3.07 \\
\hline & \multirow{4}{*}{$\mathrm{X}-\mathrm{C}$} & DMP & 2.74 & 2.68 & 2.68 & 2.71 & 2.80 & 2.722 & 0.0502 & 1.84 \\
\hline & & DEP & 2.30 & 2.31 & 2.32 & 2.32 & 2.32 & 2.314 & 0.0089 & 0.38 \\
\hline & & DBP & 1.56 & 1.67 & 1.63 & 1.51 & 1.70 & 1.614 & 0.0610 & 3.78 \\
\hline & & DOP & 1.70 & 1.72 & 1.82 & 1.86 & 1.86 & 1.792 & 0.0769 & 4.29 \\
\hline \multirow{8}{*}{ Mixture2 } & \multirow{4}{*}{$X-A$} & $\mathrm{DMP}$ & 4.01 & 4.20 & 4.11 & 4.06 & 4.04 & 4.084 & 0.0743 & 1.82 \\
\hline & & DEP & 3.44 & 3.47 & 3.42 & 3.46 & 3.40 & 3.438 & 0.0286 & 0.83 \\
\hline & & DBP & 2.63 & 2.65 & 2.64 & 2.60 & 2.67 & 2.638 & 0.0258 & 0.98 \\
\hline & & DOP & 2.19 & 2.10 & 2.14 & 2.16 & 2.09 & 2.136 & 0.0415 & 1.94 \\
\hline & \multirow{4}{*}{$X-C$} & DMP & 4.96 & 4.80 & 4.98 & 4.91 & 4.89 & 4.908 & 0.0704 & 1.43 \\
\hline & & DEP & 3.04 & 3.22 & 3.08 & 3.13 & 3.16 & 3.126 & 0.0698 & 2.23 \\
\hline & & DBP & 2.91 & 2.90 & 2.68 & 2.81 & 2.87 & 2.834 & 0.0944 & 3.33 \\
\hline & & DOP & 2.25 & 2.14 & 2.51 & 2.25 & 2.16 & 2.262 & 0.0975 & 3.52 \\
\hline
\end{tabular}

\subsubsection{Analysis of SPE Results of PAEs}

The spiked outflow curves of the water and vitamin drinks are showed in this experiment (Figure 9). Table 9 shows the experimental results of SPE spiked recoveries of phthalate esters in two beverage samples with COF materials as SPE adsorbents. The recoveries of phthalate esters in water were $97.99-100.56 \%$, and the recoveries of PAEs in vitamin drinks were $97.93-100.23 \%$. The experimental results proved that the recoveries of four phthalate esters with two self-made COF materials as SPE fillers met the requirements for the detection and analysis of trace PAEs. The two types of COFs could be used as SPE fillers in the enrichment, detection, and showed good anti-interference ability.
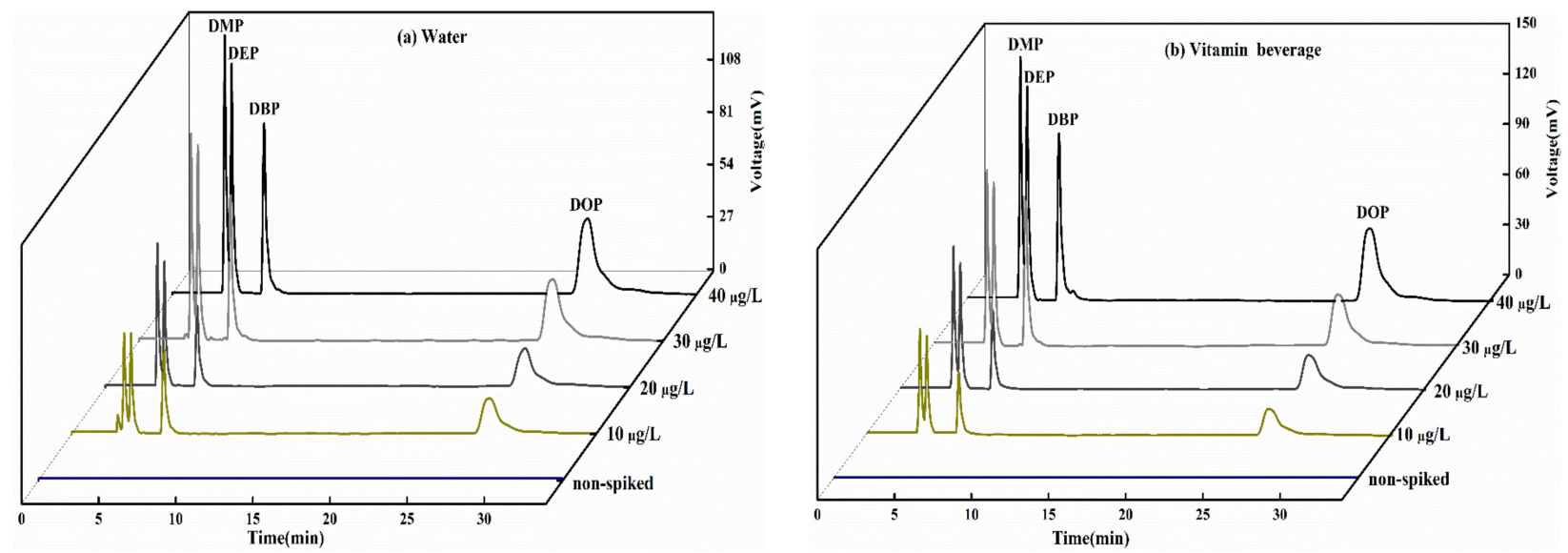

Figure 9. (a) Labeled outflow curve of water. (b) Labeled outflow curve of vitamin beverage. 
Table 9. Analysis of labeled recovery.

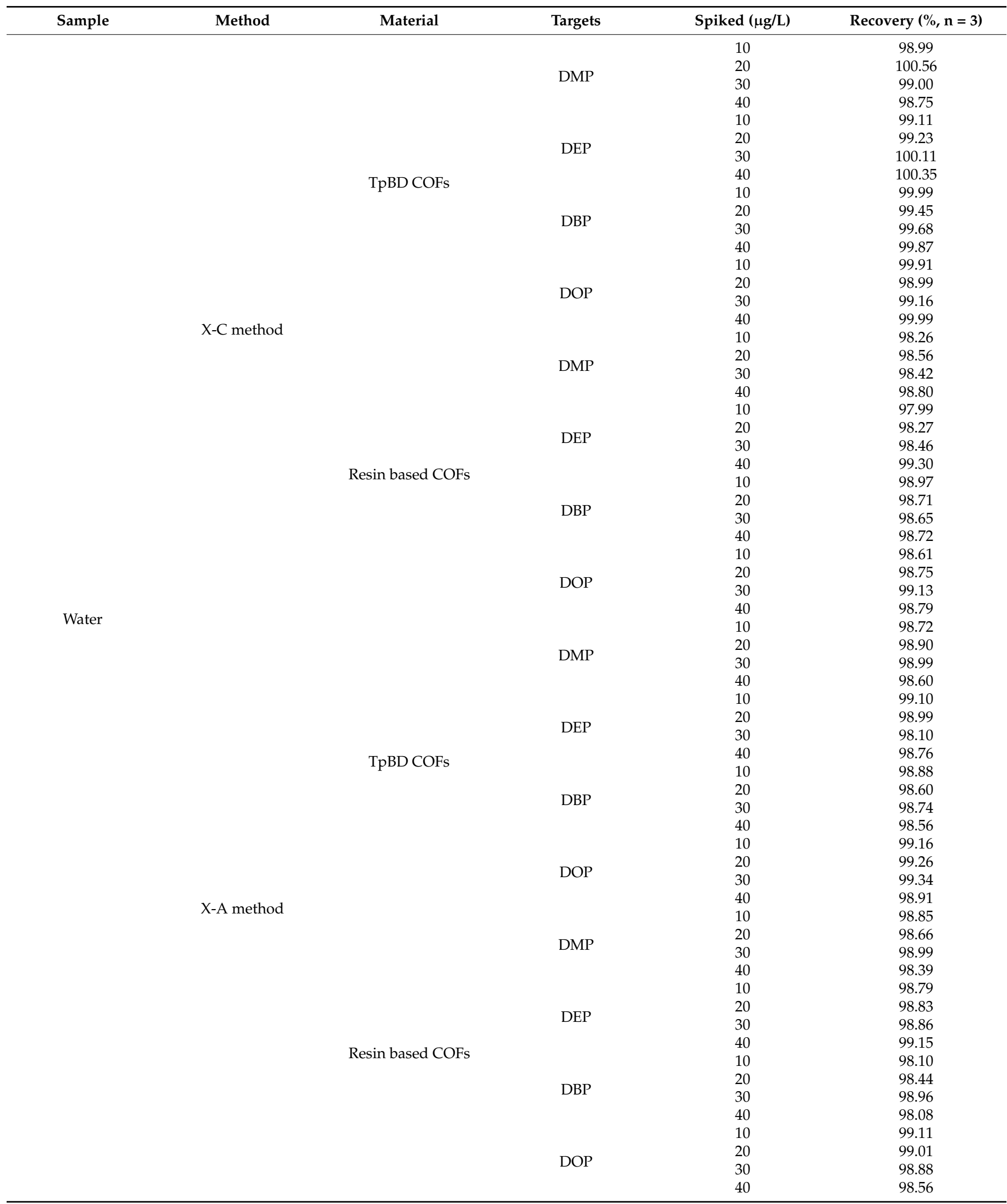


Table 9. Cont.

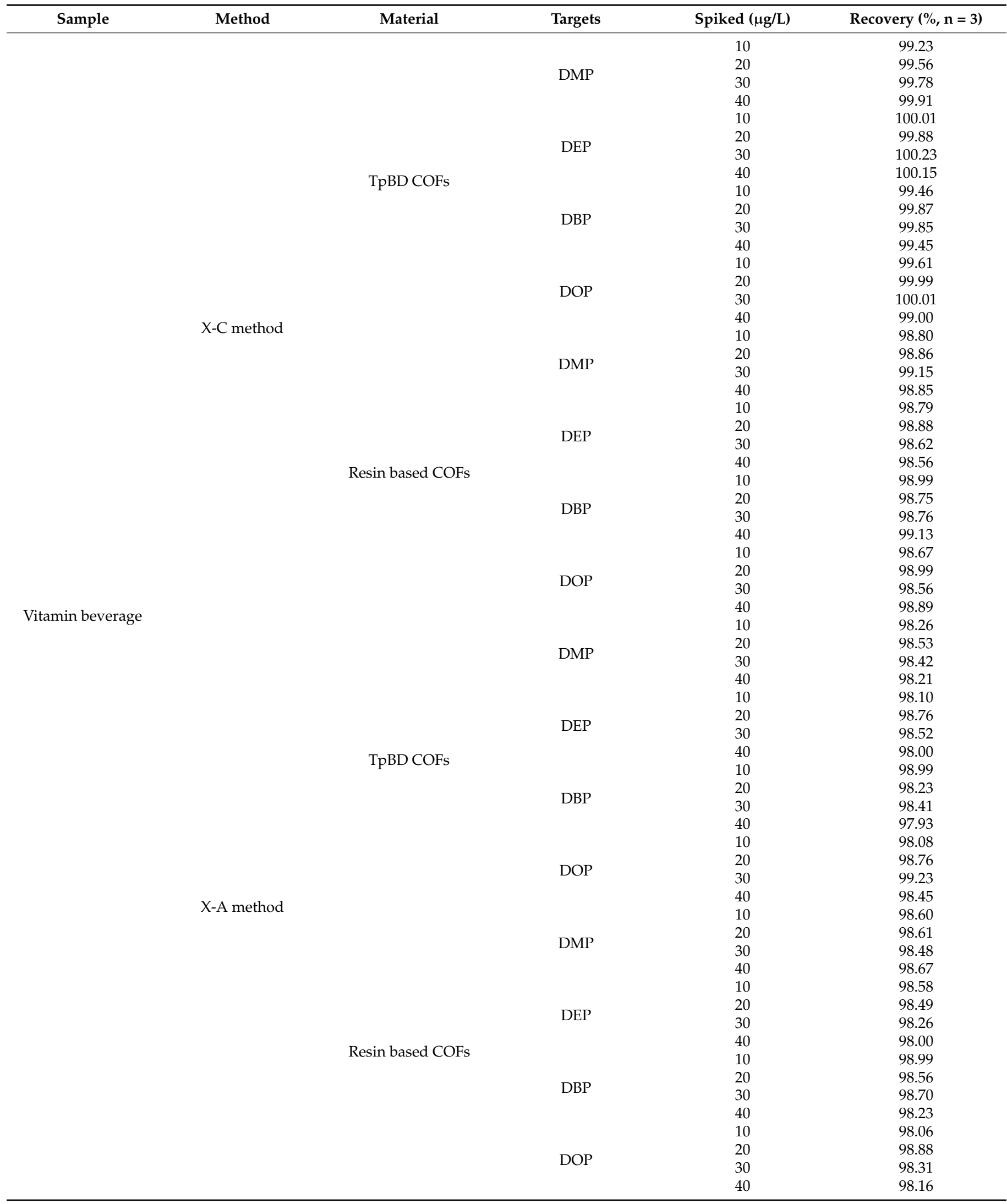




\subsubsection{Evaluation of Reuse Effect of Two COFs by SPE}

In order to investigate the reusability of the material, the experiment conducted a reusability experiment (Figure 10, Figure S3). The results proved that the recovery rate of the material did not decrease significantly after 50 repeated SPE experiments, and the recovery rates still were between $97-101 \%$, indicating that the material could be reused. When comparing the repeatability of commercial and self-made SPE filler columns, it is found that the recovery rate of commercial SPE filler columns is much lower than that of self-made SPE filler columns (see supporting information). From the perspective of cost, it could be found that the prepared resin-based COF material was more suitable for actual production.

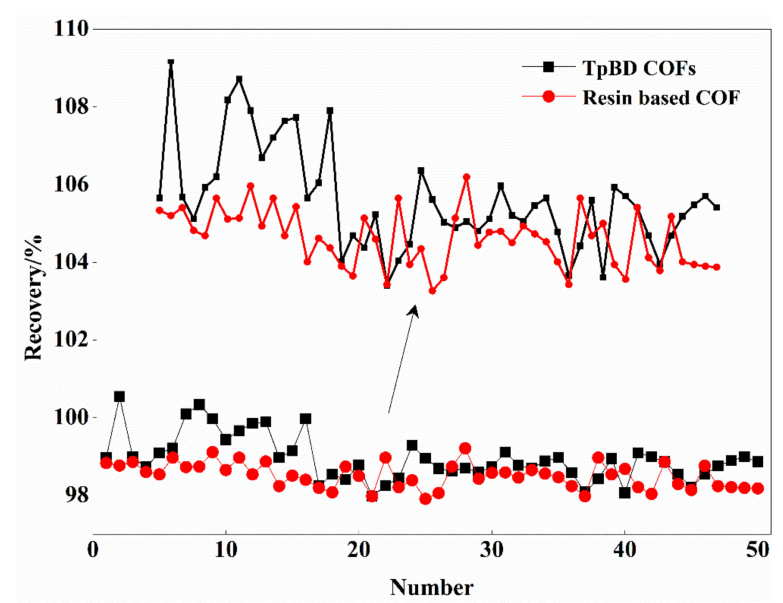

Figure 10. Recovery rate of SPE of materials.

\section{Conclusions}

Two kinds of COFs (TpBD COFs and resin-based COFs) were prepared. The feasibility of using COFs as SPE fillers to detect four PAEs (DMP, DEP, DBP, and DOP) in beverages were investigated. The adsorption performance of two kinds of COFs on PAEs was analyzed by frontal chromatography, and the solid phase extraction scheme was optimized, and the effect of SPE was evaluated.

(1) Adsorption experiments showed that the kinetic adsorption behavior of COF materials for PAEs was more consistent with the quasi-second-order kinetic adsorption model, and the static adsorption behavior is more in line with the Freundlich isothermal adsorption model.

(2) Two COF materials were applied to the SPE of PAEs samples. The recoveries were $97.99-100.56 \%$ and $97.93-100.23 \%$, respectively. The most suitable solid phase extraction schemes are X-A and X-C. These two COFs had ideal enrichment and separation effect on four phthalate esters, and had strong anti-interference ability. The SPE effects were better than four commercially available SPE columns.

(3) The preparation cost of COF materials was greatly reduced after COF materials are compounded with resin. This study provided a new way to introduce COF materials as high performance SPE adsorbent for the preconcentration and determination of trace harmful substances in beverage samples.

Supplementary Materials: The following are available online at https://www.mdpi.com/article/10 $.3390 /$ w13233338/s1, Figure S1. UV spectrum of phthalate and its spiked solution, Figure S2. X-C solid phase extraction scheme without acid and alkali, Figure S3. reusability of commercial solid phase extraction column. 
Author Contributions: Y.M. and W.Z. conceived and designed the experiments; Y.R. performed the experiments; W.Z., Y.M. and S.W. analyzed the data; L.Z., X.G. and H.C. contributed reagents/materials/ analysis tools; Y.M. wrote the paper. All authors have read and agreed to the published version of the manuscript.

Funding: The research was supported by National Natural Science Foundation of China (NO. B080404), Education Department Foundation of Liaoning Province, China (NO. LJKZ0300, NO. 2019LNJC05) and Postgraduate innovation Foundation of University of Science and Technology, Liaoning (NO. LKDYC202013).

Institutional Review Board Statement: Not applicable.

Informed Consent Statement: Not applicable.

Data Availability Statement: The data presented in this study are available on request from the corresponding author.

Conflicts of Interest: The authors declare no conflict of interest.

\section{References}

1. Amanzadeh, H.; Yamini, Y.; Moradi, M.; Asl, Y.A. Determination of phthalate esters in drinking water and edible vegetable oil samples by headspace solid phase microextraction using graphene/polyvinylchloride nanocomposite coated fiber coupled to gas chromatography-flame ionization detector. J. Chromatogr. A 2016, 1465, 38-46. [CrossRef]

2. Barp, L.; Purcaro, G.; Franchina, F.A.; Zoccali, M.; Sciarrone, D.; Tranchida, P.Q.; Mondello, L. Determination of phthalate esters in vegetable oils using direct immersion solid-phase microextraction and fast gas chromatography coupled with triple quadrupole mass spectrometry. Anal. Chim. Acta 2015, 887, 237-244. [CrossRef]

3. Jing, Y.; Li, L.; Zhang, Q.; Lu, P.; Liu, P.; Lu, X. Photocatalytic Ozonation of Dimethyl Phthalate over TiO 2 Prepared by a Hydrothermal Method. J. Hazard. Mater. 2011, 189, 40-47. [CrossRef] [PubMed]

4. Xu, B.; Gao, N.Y.; Sun, X.F.; Xia, S.J.; Rui, M.; Simonnot, M.O.; Causserand, C.; Zhao, J.F. Photochemical degradation of diethyl phthalate with $\mathrm{UV} / \mathrm{H}_{2} \mathrm{O}_{2}$. J. Hazard. Mater. 2007, 139, 132-139. [CrossRef]

5. Liao, W.; Zheng, T.; Wang, P.; Tu, S.; Pan, W. Efficient microwave-assisted photocatalytic degradation of endocrine disruptor dimethyl phthalate over composite catalyst ZrOx/ZnO. J. Environ. Sci. 2010, 22, 1800-1806. [CrossRef]

6. Higuchi, T.T.; Palmer, J.S.; Gray, L.E.; Veeramachaneni, D.N., Jr. Effects of dibutyl phthalate in male rabbits following in utero, adolescent, or postpubertal exposure. Toxicol. Sci. 2003, 72, 301-313. [CrossRef]

7. Higuchi, A.; Yoon, B.O.; Kaneko, T.; Hara, M.; Maekawa, M.; Nohmi, T. Separation of endocrine disruptors from aqueous solutions by pervaporation: Dioctylphthalate and butylated hydroxytoluene in mineral water. J. Appl. Polym. Sci. 2004, 94, 1737-1742. [CrossRef]

8. Zhou, S.; Han, M.; Ren, Y.; Yang, X.; Duan, L.; Zeng, Y.; Li, J. Dibutyl phthalate aggravated asthma-like symptoms through oxidative stress and increasing calcitonin gene-related peptide release. Ecotoxicol. Environ. Saf. 2020, 199, 110740. [CrossRef] [PubMed]

9. Semsarzadeh, M.A.; Mehrabzadeh, M.; Arabshahi, S.S. Dynamic mechanical behavior of the dioctyl phthalate plasticized polyvinyl chloride-epoxidized soya bean oil. Eur. Polym. J. 2002, 38, 351-358. [CrossRef]

10. Mayer, F.L.; Stalling, D.L.; Johnson, J.L. Phthalate Esters as Environmental Contaminants. Nature 1972, 238, 411-413. [CrossRef] [PubMed]

11. Song, D.; Sun, H.; Yang, Y.; Wang, X.; Sun, Y.; Liu, X.; Huang, M.; Feng, C.; Zhuang, Y.; Zhang, J.; et al. Status of phthalate esters in tobacco cultivation soils and its health risk to Chinese people. J. Soil. Sediments 2020, 21, 307-318. [CrossRef]

12. Tles, S.; Kartal, C. Solid-Phase Extraction (SPE): Principles and Applications in Food Samples. Acta Sci. Pol. Technol. Aliment. 2016, 15, 5-15. [CrossRef]

13. Pollak, P.T.; Carruthers, S.G.; Freeman, D.J. Simplified liquid-chromatographic assay of amiodarone and desethylamiodarone after solid-phase extraction. Clin. Chem. 1986, 32, 890-893. [CrossRef] [PubMed]

14. Xu, L.; Qiao, X.; Ma, Y.; Zhang, X.; Xu, Z. Preparation of a Hydrophilic Molecularly Imprinted Polymer and Its Application in Solid-Phase Extraction to Determine of Trace Acrylamide in Foods Coupled with High-Performance Liquid Chromatography. Food Anal. Methods 2013, 6, 838-844. [CrossRef]

15. Hallaj, T.; Amjadi, M. A sensitive plasmonic probe based on in situ growth of a Ag shell on a Au@N-CD nanocomposite for detection of isoniazid in environmental and biological samples. New J. Chem. 2019, 43, 5980-5986. [CrossRef]

16. Pfa, B.; Ad, A.; Gma, C.; Cc, C.; Dddde, F.; Vpa, B. Biopolymers in sorbent-based microextraction methods. Trends Anal. Chem. 2021, 125, 115839. [CrossRef]

17. Faraji, M.; Shirani, M.; Rashidi-Nodeh, H. The recent advances in magnetic sorbents and their applications. Trends Anal. Chem. 2021, 141, 116302. [CrossRef]

18. Jing, W.; Wag, J.; Kuiqers, B.; Bi, W.; Ddyca, B. Recent applications of graphene and graphene-based materials as sorbents in trace analysis. Trends Anal. Chem. 2021, 137, 116212. [CrossRef] 
19. Janczura, M.; Luliński, P.; Sobiech, M. Imprinting technology for effective sorbent fabrication: Current state-of-art and future prospects. Materials 2021, 14, 1850. [CrossRef] [PubMed]

20. Bazargan, M.; Ghaemi, F.; Amiri, A.; Mirzaei, M. Metal-organic framework-based sorbents in analytical sample preparation. Coord. Chem. Rev. 2021, 445, 214107. [CrossRef]

21. Yaghi, O.M. Reticular Chemistry-Construction, Properties, and Precision Reactions of Frameworks. J. Am. Chem. Soc. 2016, 138, 15507-15509. [CrossRef]

22. Ding, S.Y.; Wang, W. Covalent organic frameworks (COFs): From design to applications. Chem. Soc. Rev. 2013, 42, 548-568. [CrossRef]

23. Montoro, C.; Rodríguez-San-Miguel, D.; Polo, E.; Escudero-Cid, R.; Ruiz-González, M.L.; Navarro, J.A.; Ocón, P.; Zamora, F. Ionic Conductivity and Potential Application for Fuel Cell of a Modified Imine-Based Covalent Organic Framework. J. Am. Chem. Soc. 2017, 139, 10079-10086. [CrossRef] [PubMed]

24. Ma, Y.J.; Yuan, Y.; Gao, X.; Cui, H.; Zhang, W.; Wang, S.Y. Preparation of a Novel Resin Based Covalent Framework Material and Its Application in the Determination of Phenolic Endocrine Disruptors in Beverages by SPE-HPLC. Polymers 2021, 13, 2935. [CrossRef]

25. Liu, J.M.; Yuan, J.L.X.Y.; Liu, H.L.; Fang, G.Z.; Wang, S. Spherical covalent organic frameworks as advanced adsorbents for preconcentration and separation of phenolic endocrine disruptors, followed by high performance liquid chromatography. RSC Adv. 2018, 8, 26880-26887. [CrossRef]

26. Shibukawa, A.; Nakagawa, T.; Nishimura, N.; Miyake, M.; Tanaka, H. Determination of free drug in protein binding equilibrium by high-performance frontal analysis using internal-surface reversed-phase silica support. Chem. Pharm. Bull. 1989, 37, 702-706. [CrossRef] [PubMed]

27. Geng, X.-D.; Regnier, F.E. Characters of the Plateau of Methanol Increment in Frontal Analysis in Reversed Phase Liquid Chromatography. Chin. J. Chem. 2010, 20, 431-440. [CrossRef]

28. Otoukesh, M.; Es'haghi, Z.; Feizy, J.; Nerin, C. Graphene oxide/Layered Double Hydroxides@ Sulfonated Polyaniline: A sorbent for ultrasonic assisted dispersive solid phase extraction of phthalates in distilled herbal beverages. J. Chromatogr. A 2020, 1625, 461307. [CrossRef] [PubMed]

29. Qian, X.; Yin, X.; Shen, Y.; Zhang, N.; Wang, M.; Gu, Z. Detection of Phthalate Esters in Environmental Water Samples-Comparison of Nylon6 Nanofibers Mat-based Solid Phase Extraction and Other Conventional Extraction Methods. Chin. J. Chem. 2011, 29, 567-574. [CrossRef]

30. Huang, Z.; Tu, C.; Liu, H.; Wang, L.; Zhu, Z.; Watanabe, I. Hollow fiber-solid phase microextraction of phthalate esters from bottled water followed by flash evaporation gas chromatography-flame ionization detection. J. Chromatogr. A 2020, 1619, 460953. [CrossRef]

31. Wu, D.; Liu, F.; Tian, T.; Wu, J.-F.; Zhao, G.-C. Copper ferrite nanoparticles as novel coating appropriated to solid-phase microextraction of phthalate esters from aqueous matrices. Microchem. J. 2021, 162, 105845. [CrossRef]

32. Khataei, M.M.; Yamini, Y.; Ghaemmaghami, M. Reduced graphene-decorated covalent organic framework as a novel coating for solid-phase microextraction of phthalate esters coupled to gas chromatography-mass spectrometry. Mikrochim. Acta 2020, 187, 256. [CrossRef] [PubMed] 